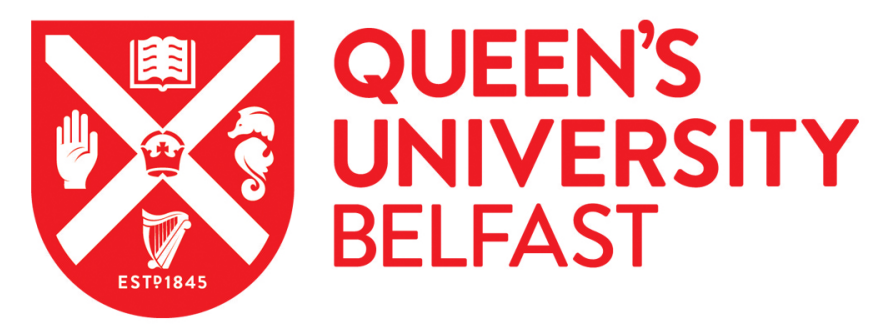

\title{
SIW slot antenna for E-band communications
}

Zelenchuk, D., Fusco, V., Breslin, J., \& Keaveney, M. (2015). SIW slot antenna for E-band communications. In Proceedings of the 45th European Microwave Conference (pp. 582-585). Institute of Electrical and Electronics Engineers Inc.. https://doi.org/10.1109/EuMC.2015.7345830

Published in:

Proceedings of the 45th European Microwave Conference

Document Version:

Peer reviewed version

Queen's University Belfast - Research Portal:

Link to publication record in Queen's University Belfast Research Portal

\begin{abstract}
Publisher rights
@ 2015 IEEE. Personal use of this material is permitted. Permission from IEEE must be obtained for all other uses, in any current or future media, including

reprinting/republishing this material for advertising or promotional purposes, creating new collective works, for resale or redistribution to servers or lists, or reuse of any copyrighted component of this work in other works.
\end{abstract}

\section{General rights}

Copyright for the publications made accessible via the Queen's University Belfast Research Portal is retained by the author(s) and / or other copyright owners and it is a condition of accessing these publications that users recognise and abide by the legal requirements associated with these rights.

Take down policy

The Research Portal is Queen's institutional repository that provides access to Queen's research output. Every effort has been made to ensure that content in the Research Portal does not infringe any person's rights, or applicable UK laws. If you discover content in the Research Portal that you believe breaches copyright or violates any law, please contact openaccess@qub.ac.uk. 


\section{SIW slot antenna for E-band communications}

\author{
Dmitry Zelenchuk, Vincent Fusco \\ ECIT, Queen's University Belfast, \\ Belfast, United Kingdom \\ d.zelenchuk@qub.ac.uk,v.fusco@qub.ac.uk
}

\author{
James Breslin, Mike Keaveney \\ Analog Devices Inc., \\ Limerick, Ireland
}

\begin{abstract}
The paper proposes novel substrate integrated waveguide (SIW) slot antenna for E-band communications. The antenna is designed at a two-layer low temperature co-fired ceramic (LTCC) substrate in $71-76 \mathrm{GHz}$ frequency band. The proposed antenna demonstrates a gain better than $11.3 \mathrm{dBi}$ and efficiency of $85 \%$ and can be used as a standalone antenna or as an element of a larger array.
\end{abstract}

Keywords-SIW, LTCC; slot antenna, E-band communications

\section{INTRODUCTION}

The large spectrum available has recently attracted attention to E-band backhaul systems [1]. Both 71-76 GHz and 81$86 \mathrm{GHz}$ band allow $10 \mathrm{GHz}$ of bandwidth for increased data rates in order to satisfy the demand on multi-gigabit wireless applications for mobile network infrastructure.

The wideband, high-gain antennas are required for these millimeter-wave applications. Due to quite stringent requirements the antenna solutions developed include horn arrays [2], lenses [3], and reflector antennas [4]. Those are bulky and can hardly be employed for compact mobile terminals. Waveguide slot antenna arrays [5] have recently been shown to provide good alternative to the bulky 3D structures. Still the manufacturing process can be precluding them from massmarket.

An alternative to the hollow waveguide is present in SIW waveguide antennas that have been successfully applied at mmwave frequencies [6]. The SIW slot arrays with multilayer corporate feed have been demonstrating wideband and high-gain performance. However, the use of subsequent interlayer slot couplers can lead to a complicated design and increases cost. In this paper, we propose a dielectric loaded SIW slot antenna that employs only two dielectric layers and designed on LTCC substrate. The antenna can be subsequently used as an antenna element in larger arrays or as a standalone component.

\section{DESIGN}

\section{A. Antenna description}

A layer structure of the LTCC antenna is shown in Fig. 1. The dielectric properties of the LTCC substrate at the design stage were specified as follows: permittivity of $7.8 \pm 0.1$ and loss tangent of 0.0014 , as given by the manufacturer. Each metal layer from top to bottom is further referred as M1, M2 and M3. The conductivity of M1 and M3 is $5.8 \times 10^{7} \mathrm{~S} / \mathrm{m}$ and of M2 and of the vias is $2.98 \times 10^{7} \mathrm{~S} / \mathrm{m}$.
The full antenna is presented in Fig. 2. It consist of 2 radiating dielectric-filled open SIW cavities. Each cavity is fed with $T E_{20}$ mode through a pair of slots and a feeding structure that described below. After each component is described, the full antenna performance and dimensions will be given. All the simulations below are performed with CST Microwave Studio.

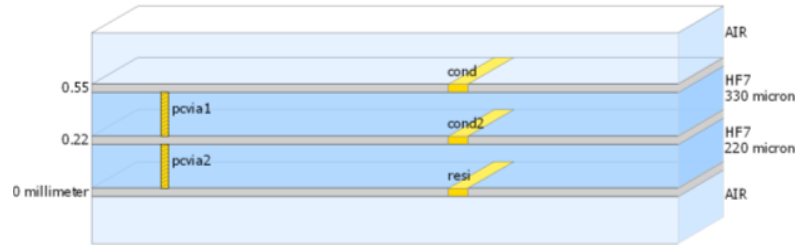

Fig. 1. LTCC layer mapping ("cond" - top metal M1, "cond2"- middle metal "M2", "resi" - bottom metal M3).

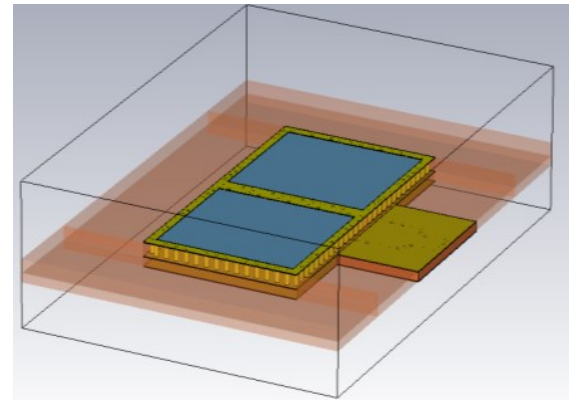

Fig. 2. 2x1 antenna array.

\section{B. Same layer launcher}

The antenna is fed from the bottom layer M3 through a CPWG-to-SIW launcher [7]. The sketch of the back-to-back test launcher and its simulated performance is presented Fig. 3. The back-to-back insertion loss is shown to be better than $0.5 \mathrm{~dB}$ and the return loss is better than $20 \mathrm{~dB}$.

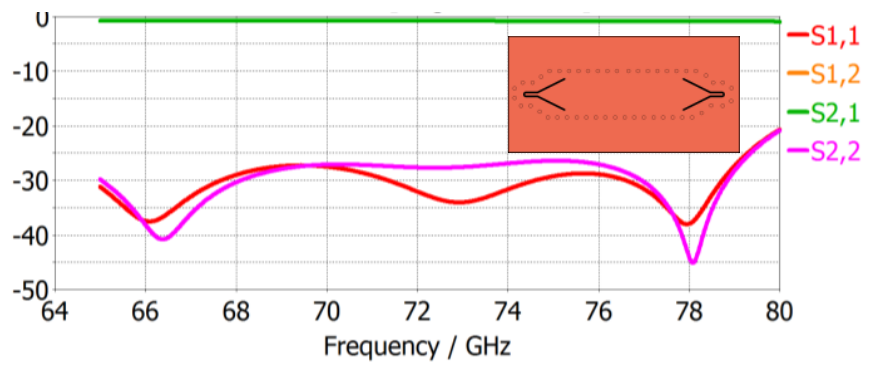

Fig. 3. Back-to-back same layer launcher performance. 


\section{Equal power splitter and TE $10-t o-T E_{20}$ mode converter}

After the energy is launched into the SIW waveguide, it is divided into two symmetrical cavities containing a symmetric pair of slots. The slots have to be excited out-of-phase to produce a sum radiation pattern and therefore the splitter which is excited with $\mathrm{TE}_{10}$ mode should equally split and convert energy into $\mathrm{TE}_{20}$ simultaneously suppressing the $\mathrm{TE}_{10}$ mode.

The designed splitter is shown in Fig. 4 and its simulated performance in Fig. 5. The simulation is performed taking into account symmetry of the structure with respect to yz-plane and symmetric excitation of $\mathrm{TE}_{10}$ mode of port 1 . By optimising positions of the posts the return and insertion loss of $\mathrm{TE}_{10}$ mode were ensured to be better than $20 \mathrm{~dB}$ for the $71-76 \mathrm{GHz}$ frequency band. The conversion from $\mathrm{TE}_{10}$ to $\mathrm{TE}_{20}$ is $3.2 \mathrm{~dB}$ and the symmetry of excitation ensures that the power is equally divided into the both arms.

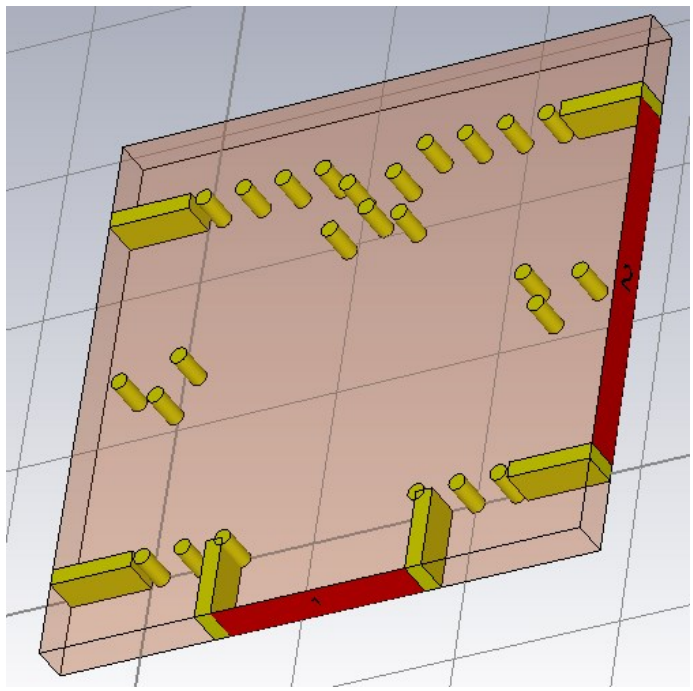

Fig. 4. Equal power splitter and converter from $\mathrm{TE}_{10}$ to $\mathrm{TE}_{20}$ mode.

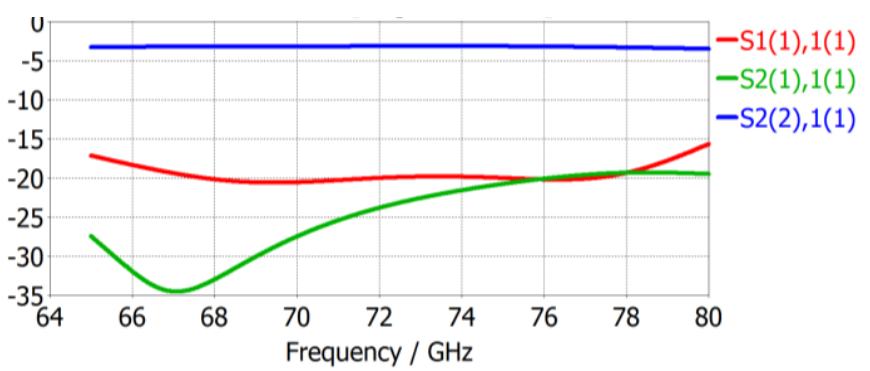

Fig. 5. The splitter-converter simulated performance. Modes (2) - $\mathrm{TE}_{20},(1)-$ $\mathrm{TE}_{10}$

\section{Radiating element}

The $T E_{20}$ mode excites it the pair of slots with a dielectric cavity on top of them, see Fig. 6. The slots are matched by positions of two tuning posts and back wall of the cavity. The energy travels through the slots into open cavity laterally bounded by via fence in order to suppress surface wave propagation. This cavity is approximately quarter wavelength long and improves the directivity of the antenna element. Our simulation shown 2-3dB improvement of the directivity for the structure with the top dielectric layer in comparison to a slot to free space interface. The simulated return loss for the structure is better than $16 \mathrm{~dB}$ as shown in Fig. 7.

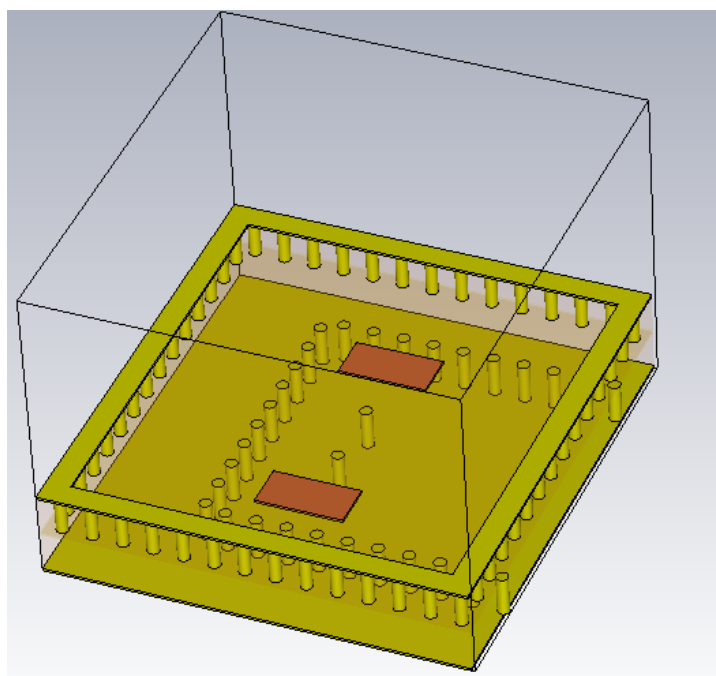

Fig. 6. 2 slot antenna element with open cavity on top of it. This view does not show M2 metal layer and shows only slots in that plane.

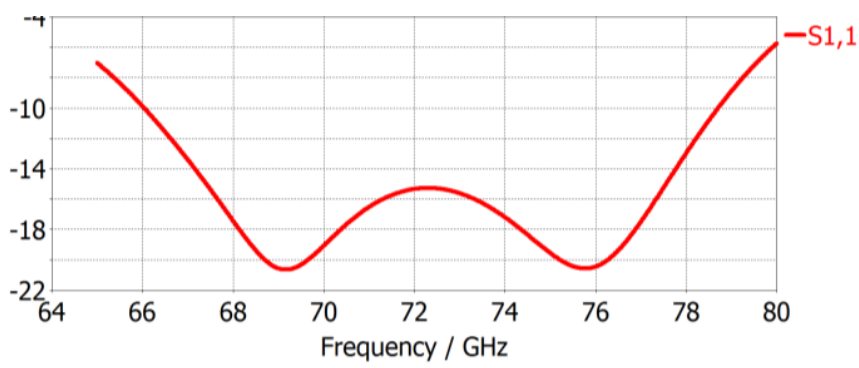

Fig. 7. Return loss of the 2 slot antenna element.

The radiation pattern of the 2 slot antenna element is shown in Fig. 8. The directivity of the antenna is about $8 \mathrm{dBi}$ and there is very little frequency dependence of the radiation pattern is demonstrated.

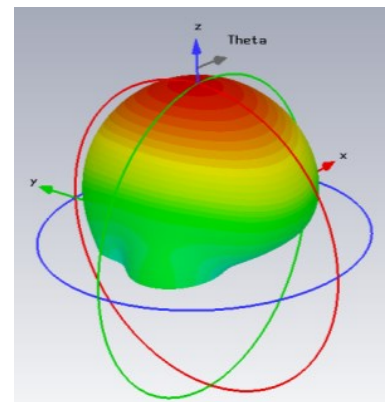

Fig. 8. 3D radiation pattern of 2 slot antenna element with open cavity at 73.5 $\mathrm{GHz}$

\section{E. Full antenna layout}

All the components presented above have been composed into a full antenna with dimensions shown in Fig. 9. 


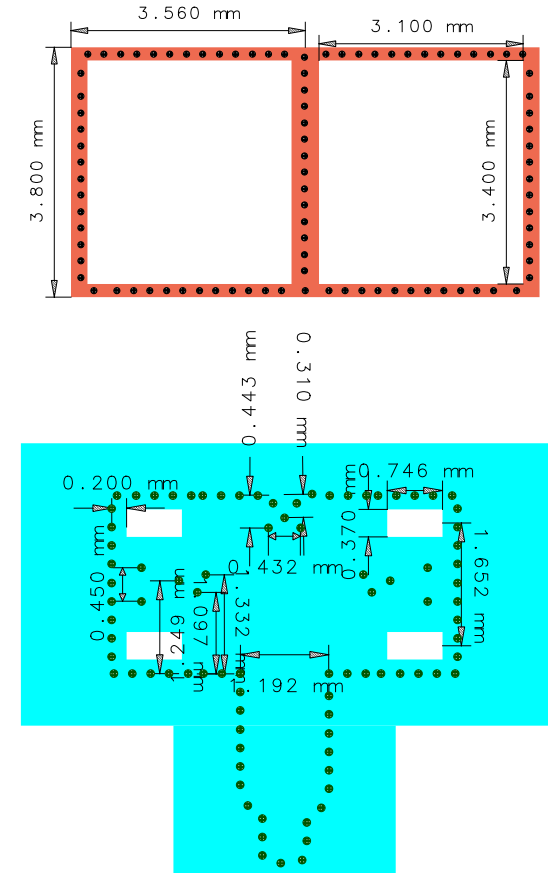

(a)

(b)

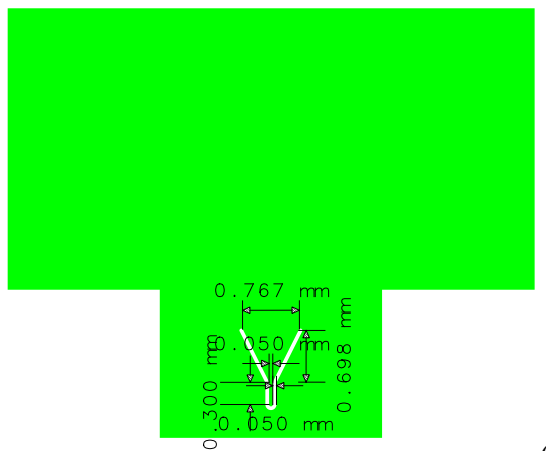

(c)

Fig. 9. The final $2 \times 1$ antenna array design with three separate layers: (a) - M1, (b) $-\mathrm{M} 2$, (c) - M3. Via diameter is $0.1 \mathrm{~mm}$ and period is $0.25 \mathrm{~mm}$

The simulated return loss of the final array are better than $12 \mathrm{~dB}$ in the band of interest, see Fig. 10. The simulated directivity is about $12 \mathrm{dBi}$. The boresight directivity variation with frequency is well within $1 \mathrm{~dB}$. The simulations have also shown that the efficiency of the antenna is about $85 \%$. The sidelobes level of the antenna varies from -10 to $-13 \mathrm{~dB}$, which is the result of bigger cavity design.

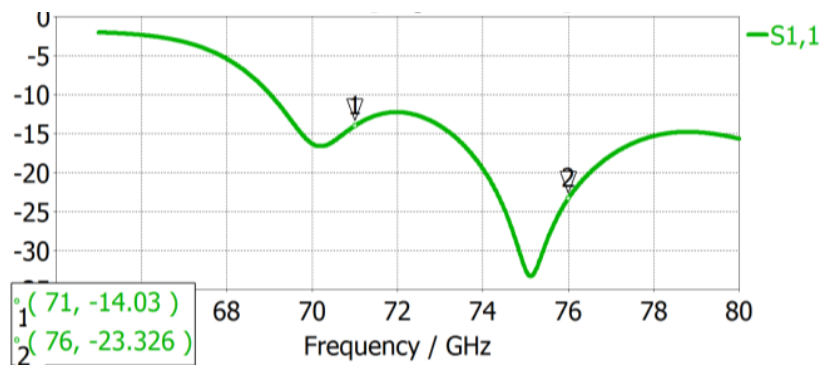

Fig. 10. Simulated return loss of the final antenna.

\section{EXPERIMENTAL RESULTS}

The antenna has been manufactured and measured. The return loss measurements were carried out on a Cascade Microtech probe station connected to Agilent PNA E8631C. The antenna was measured with Cascade Infinity GSG 150 micron pitch probe.

In separate development, it has been found out that the dielectric properties of the substrate differ from the nominal ones specified by the manufacturer. There were two different figures of merit obtained: one is by fitting S-parameters for a back-toback transition $\left(\varepsilon_{r}=7.95, \tan \delta=0.0043\right.$ for all layers $)$ and the other by measurement of SIW resonators at each layer $\left(\varepsilon_{r 1}=\right.$ $\left.7.95, \tan \delta_{1}=0.0043, \varepsilon_{r 2}=8.03, \tan \delta_{1}=0.0038\right)$. The measured results are compared against the two simulations in Fig. 11. The measured return loss is $9 \mathrm{~dB}$ at $72 \mathrm{GHz}$ and better than $10 \mathrm{~dB}$ in the rest of the band. It appears that the measured dielectric properties provide more accurate results in the simulation and will be employed in the future work.

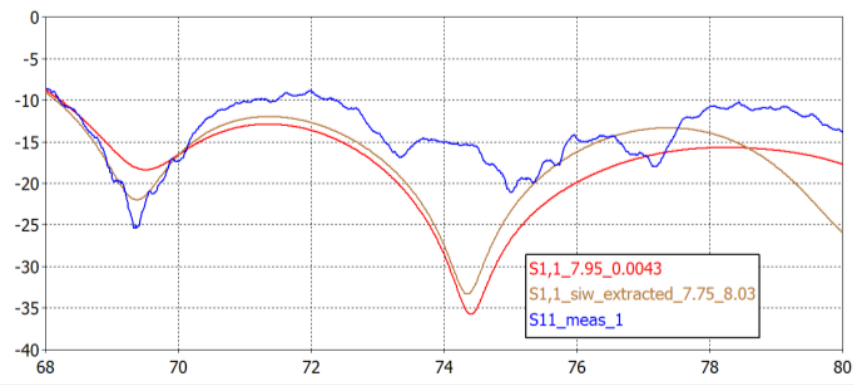

Fig. 11. Comparison of the measured and simulated return loss.

For radiation pattern measurement the antenna was in $\mathrm{Rx}$ mode and fed by a GSG-WR15 probe connected to a V-band mixer as shown in Fig. 12. The antenna was mounted on a fixture and placed on rotating pole within an anechoic chamber. It has been illuminated by a $20 \mathrm{dBi}$ standard horn placed at a distance of $1 \mathrm{~m}$.

The wooden fixture does not significantly interfere with the measurement as it comes into view of the antenna at wide angle where the received signal is low.

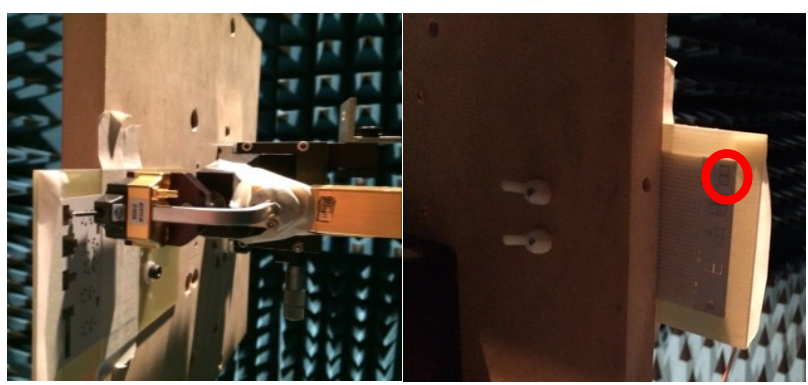

(a)

(b)

Fig. 12. Radiation pattern measurement setup. Feeding arrangement (a) and the radiation aperture side of the antenna (b).

The comparison of the measured radiation pattern with the simulated one is given in Fig. 13. The measured pattern at $72.7 \mathrm{GHz}$ is in very good agreement with simulation in both planes; the sidelobes level is $10 \mathrm{~dB}$ as predicted. The measured 
level of cross-polarization is better than $20 \mathrm{~dB}$ as shown in Fig. 14.

The gain of the antenna was measured with 3-antenna method by employing two additional $20 \mathrm{dBi}$ standard horn antennas and a power meter. The measured gain varies from 11.9 to $11.3 \mathrm{dBi}$ at $75-77 \mathrm{GHz}$ band, as shown in Fig. 15 . The gain is not measured at lower frequencies due to lack of instruments during the measurements. Nevertheless, there is no significant gain variation expected at lower frequencies. The efficiency estimated by subtracting measured gain from simulated directivity is obtained as $85 \%$.
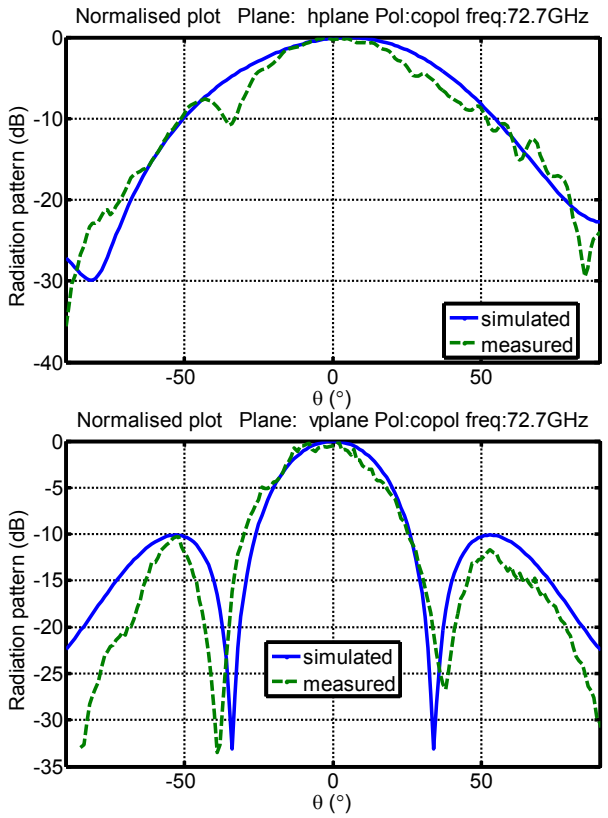

Fig. 13. Comparison of the simulated and measured radiation patterns.

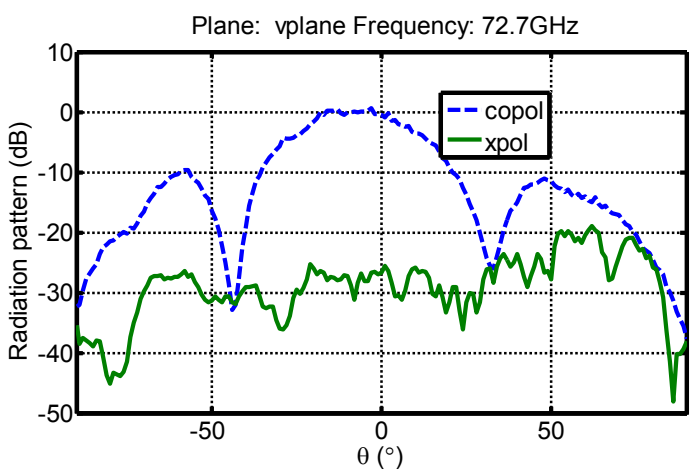

Fig. 14. Measured normalized radiation patterns of copolar and cross-polar components at vertical plane at $72.7 \mathrm{GHz}$.

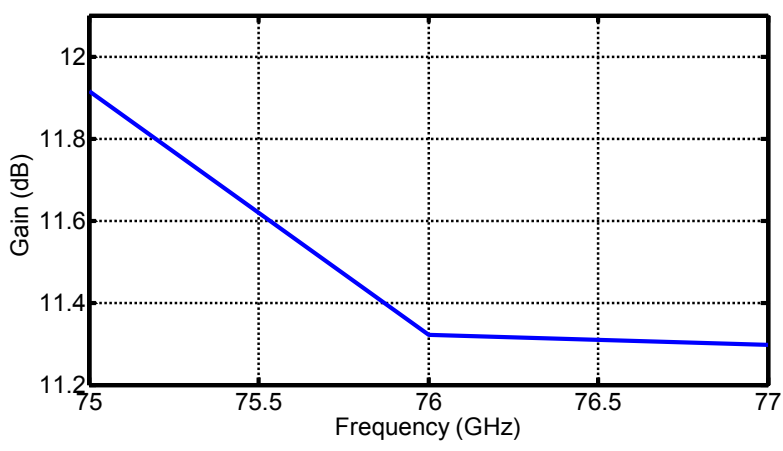

Fig. 15. Measured gain of the antenna under test.

\section{CONCLUSION}

A novel substrate integrated waveguide (SIW) slot antenna for E-band communications has been proposed in the paper. The antenna has been designed at two-layer LTCC substrate in 71$76 \mathrm{GHz}$ frequency band. The measured return loss is below $9 \mathrm{~dB}$ at $72 \mathrm{GHz}$ and better than $10 \mathrm{~dB}$ in the rest of the band. The measured radiation pattern and the simulated one are in good agreement. The cross-polarization level is below $20 \mathrm{~dB}$ and the measured gain is above $11.3 \mathrm{dBi}$. The proposed antenna can be used as a standalone antenna or as an element of a larger array manufactured on a two-layer LTCC substrate.

\section{ACKNOWLEDGMENT}

The authors are grateful to Analog Devices Inc for facilitating the manufacturing process and TDK for manufacturing of the samples and providing the data on the manufacturing process.

\section{REFERENCES}

[1] J. A. Zhang, W. Ni, J. Matthews, C.-K. Sung, X. Huang, H. Suzuki, and I. Collings, "Low latency integrated point-to-multipoint and e-band point-topoint backhaul for mobile small cells," in 2014 IEEE International Conference on Communications Workshops (ICC), 2014, pp. 592-597.

[2] M. B. Gueye, H. H. Ouslimani, S. N. Burokur, A. Priou, Y. Letestu, and A. Le Bayon, "Antenna array for point-to-point communication in E-band frequency range," in IEEE Antennas and Propagation Society, AP-S International Symposium (Digest), 2011, pp. 2077-2079.

[3] M. K. T. Al-Nuaimi, W. Hong, and Y. Zhang, "Design of high-directivity compact-size conical horn lens antenna," IEEE Antennas Wirel. Propag. Lett., vol. 13, pp. 467-470, 2014.

[4] I. Papageorgiou, A. Derneryd, L. Manholm, and J. Yang, "An E-band cylindrical reflector antenna for wireless communication systems," in 7th European Conference onAntennas and Propagation (EuCAP), 2013, pp. 524528.

[5] M. Zhang, J. Hirokawa, and M. Ando, "An E-Band Partially Corporate Feed Uniform Slot Array With Laminated Quasi Double-Layer Waveguide and Virtual PMC Terminations," IEEE Trans. Antennas Propag., vol. 59, no. 5, pp. 1521-1527, May 2011.

[6] J. Xu, Z. N. Chen, X. Qing, and W. Hong, "140-GHz TE20-mode dielectric-loaded SIW Slot antenna array in LTCC," IEEE Trans. Antennas Propag., vol. 61, no. 4, pp. 1784-1793, 2013.

[7] D. Zelenchuk, A. J. Martinez-Ros, T. Zvolensky, J. L. Gomez-Tornero, G. Goussetis, N. Buchanan, D. Linton, and V. Fusco, "W-Band Planar WideAngle Scanning Antenna Architecture," J. Infrared, Millimeter, Terahertz Waves, vol. 34, no. 2, pp. 127-139, Jan. 2013. 